American Journal of Environmental Sciences 5 (1): 111-115, 2009

ISSN $1553-345 \mathrm{X}$

(C) 2009 Science Publications

\title{
Seasonal Distribution of Organic Carbon in the Surface Sediments of the Terengganu Nearshore Coastal Area
}

\author{
${ }^{1}$ S. Hasrizal, ${ }^{4}$ B.Y. Kamaruzzaman, ${ }^{1}$ I. Sakri, ${ }^{2}$ M.C. Ong and ${ }^{3}$ M.S. Noor Azhar \\ ${ }^{1}$ Faculty of Agrotechnology and Food Science, \\ University Malaysia Terengganu, 21030 Kuala Terengganu, Malaysia \\ ${ }^{2}$ Faculty of Maritime Studies and Marine Science, \\ University Malaysia Terengganu, 21030 Kuala Terengganu, Malaysia \\ ${ }^{3}$ Institute of Oceanography, \\ University Malaysia Terengganu, 21030 Kuala Terengganu, Malaysia \\ ${ }^{4}$ Institute of Oceanography and Maritime Studies, International Islamic University Malaysia, \\ Jalan Istana, Bandar Indera Mahkota, 25200 Kuantan, Pahang, Malaysia
}

\begin{abstract}
Problem statement: The distribution of organic carbon in the surface sediment is a crucial indicator for current productivity in the ocean especially in the nearshore area. The difference of organic carbon in the surface sediment reflects the influence of current movement on the bottom sediment. Approach: This study was carried out to oversee the difference of organic carbon distribution during pre and post-monsoon seasons. For the purpose of the study, 42 surface sediments in the Terengganu near shore area were collected and determined for organic carbon by using the wet dichromate acid method. Results: The concentration of organic carbon was significantly different between the seasons showing a relatively higher content during pre-monsoon seasons. In this study, the average concentration of organic carbon in pre-monsoon was $1.14 \pm 0.29 \%$ and varied from $0.60-1.80 \%$. Meanwhile during post-monsoon seasons, the average concentration of organic carbon was slightly lower to $0.82 \pm 0.23 \%$ and ranged from $0.24-1.32 \%$. Conclusion: Generally, the average concentration of organic carbon in South China Sea was low compared to the occurrence in riverine environment as well as the mangrove environment.
\end{abstract}

Key words: Organic carbon, pre-monsoon, post-monsoon, terengganu nearshore

\section{INTRODUCTION}

Terengganu water experienced the semi annual reversal in the wind system and the reversal in the current flow, in the upper layer of the ocean. Due to this reason, a north east monsoon season and a south east monsoon season, can be clearly distinguished in the South China Sea. Their coastal near shore areas are active sites where huge amount of organic matter is introduced into the ocean system through river runoff, in situ primary production and anthropogenic impacts. Interaction between a complex mixture of organics and inorganic enhances active material cycling's in time and space. However, different factors may control the partitioning and also the bioavailability of the hydrophobic organic compound pollutants within the benthic ecosystem. These factors include various sediment characteristics, such as grain size distribution, mineral composition and organic content ${ }^{[1,2,3]}$. Surface sediments may be resuspended and redistributed by the action of waves and currents ${ }^{[4,5]}$. As these phenomena erode the top most layers of the sediment column, resuspended sediments contain recently deposited organic matter. In shallow water bodies of about a few meters deep, this matter may be rich in easily degradable fractions, as debris from dead marine organisms may rapidly settle onto the sediment surface. Therefore, through the processes of sediment resuspension and redistribution, organic matter at the sediment-water interface may be a significant source of easily remineralizable materials.

Only limited work has been done on the organic matter, both in the sediment and in the suspended sediment in Malaysian water. Although there have been

Corresponding Author: B.Y. Kamaruzzaman, Institute of Oceanography and Maritime Studies, International Islamic University Malaysia, Jalan Istana, Bandar Indera Mahkota, 25200 Kuantan, Pahang, Malaysia 
many studies of the distribution of particulate organic carbon in suspended matter in sea water and in the bottom sediments in South China Sea and adjacent seas $^{[6,7]}$, data on the coastal water and rivers of Malaysia are still limited. In recent years, the study area especially near the Terengganu and Kemaman estuaries has been heavily impacted by discharges from municipal and industrial outflows. This was due to the rapid development of the area via expansion of the industrialization area as well as the increase in population. Steel and petro-chemicals are the main industry in the area and is the catalyst for other supportive industries to develop around the same area. The aim of this work was to determine the seasonal effects of organic carbon distribution in the area.

\section{MATERIALS AND METHODS}

Study site: The South China Sea occupies the northern tropic and is influences by monsoonal climate which consist by south west monsoon that is prevail in summer and north east monsoon that is prevail during the winter season. Study area was experiencing the seasonal wind of north east monsoon that was usually prevailed from mid of October to February. The near shore mean daily tidal range is about $1.83 \mathrm{~m}$ and the maximum value was recorded $3.05 \mathrm{~m}$ during the northeast monsoon. Basically, Terengganu water accumulates the sediment sources from some largest river in Terengganu like Terengganu River, Kerteh River and Kemaman River.

This study was conducted using the research vessel of Unipertama VI with 42 surface sediments were collected in Terengganu water by using Smith McIntyre Grab (Fig. 1). The determination of organic carbon was determined using the wet dichromate acid method. For the organic carbon in the sediment, sediment were dried in an oven at $45^{\circ} \mathrm{C}$ and grounded in an agate mortar.

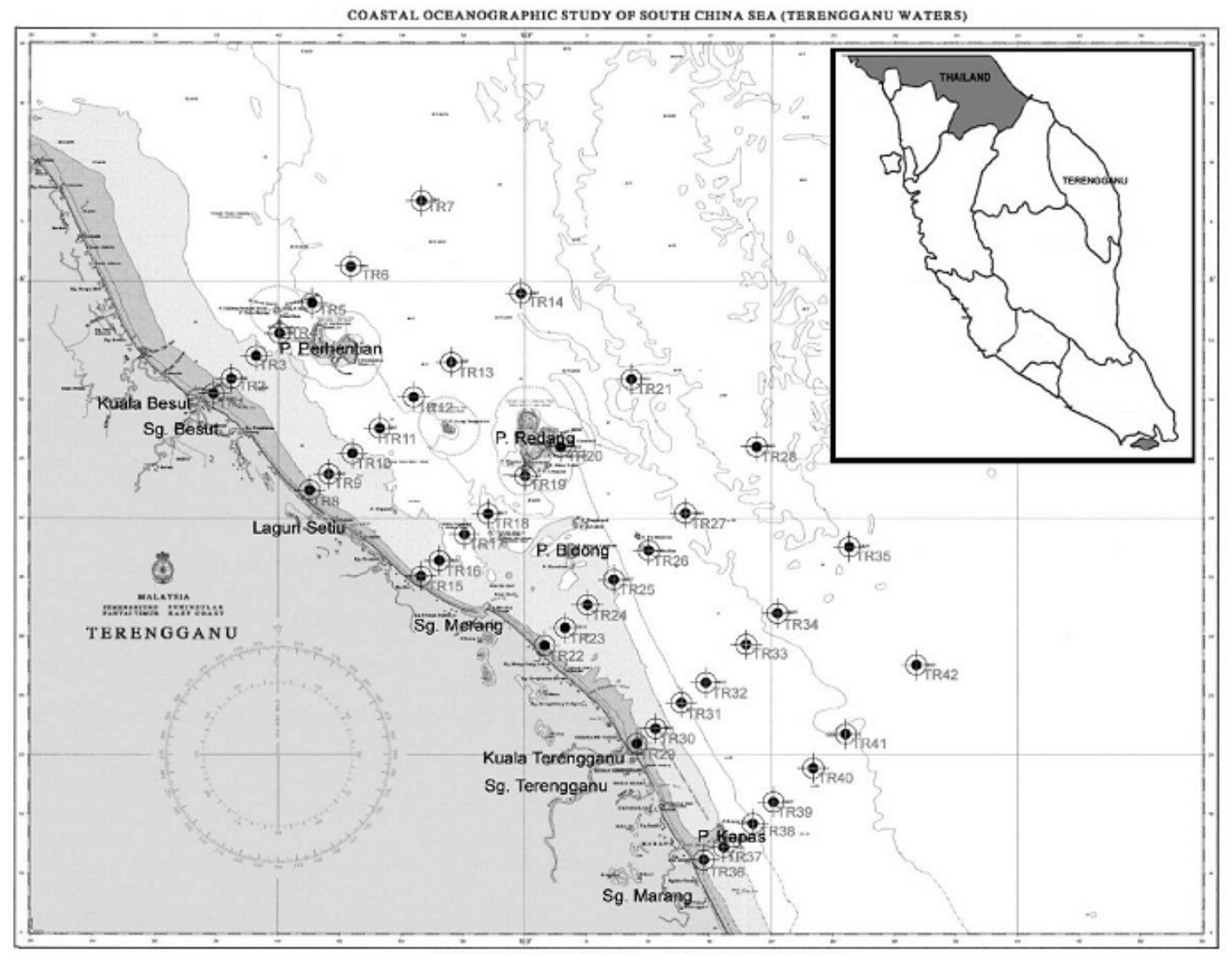

Fig. 1: Geographical position of 42 sampling stations in Terengganu coastal water 
The samples were then sieved through a $63 \mu \mathrm{m}$, without dispersion agent, to avoid contamination of the samples. The sediment were then labeled and stored at room temperature for the laboratory analysis. The organic carbon in this study were determined using the total organic carbon analyzer, model TOC-V 5000/5050, Shimadzu, Japan. Briefly, about $20 \mathrm{mg}$ sediment samples were weighted in the tin crucible sample boats and were burnt in the furnace for $30 \mathrm{~min}$ at temperature $900^{\circ} \mathrm{C}$. The total organic carbon was then calculated by subtracting the Inorganic Carbon (IC) from the Total Carbon (TC) that was obtained from the total organic carbon analyzer. The precision assessed by replicate analyses was within 3\%. The accuracy was also examined by analyzing, in duplicate a Reference Materials of glucose and the results coincided with the certified values within a difference of $\pm 3 \%$.

\section{RESULTS}

Little information is available on the organic carbon aspects of the Terengganu coastal and generally like most other coastal environments; their environmental characteristics such as the sediment characteristics and organic carbon content are much influenced by tidal rhythm and monsoon cycle. Their distributions are much dependent upon the combination of physical forces such as freshwater runoff, tidal currents and waves ${ }^{[8]}$. In this study, the organic carbon distribution in surface sediment for pre and post-monsoon season are shown in Fig. 2a and $b$. Their average concentration of organic carbon in pre-monsoon was $1.14 \pm 0.29 \%$ and varied from $0.60-1.80 \%$. However, during post-monsoon the average of organic carbon concentration was observed to have relatively lower value with $0.82 \pm 0.23 \%$ and ranged from $0.24-1.32 \%$. This was proven by the anova statistical analysis, where it shows a significant different $(\mathrm{p}<0.05)$ of organic carbon content between the sampling points and the both of pre and post monsoon seasons.

\section{DISCUSSION}

High organic carbon concentrations could be primarily caused by the river run-off, which seem to have been the main supply of organic matter into the coastal area. The organic carbon may also have been due to the activity of aquatic organisms, mainly photosynthetic and benthic organisms,

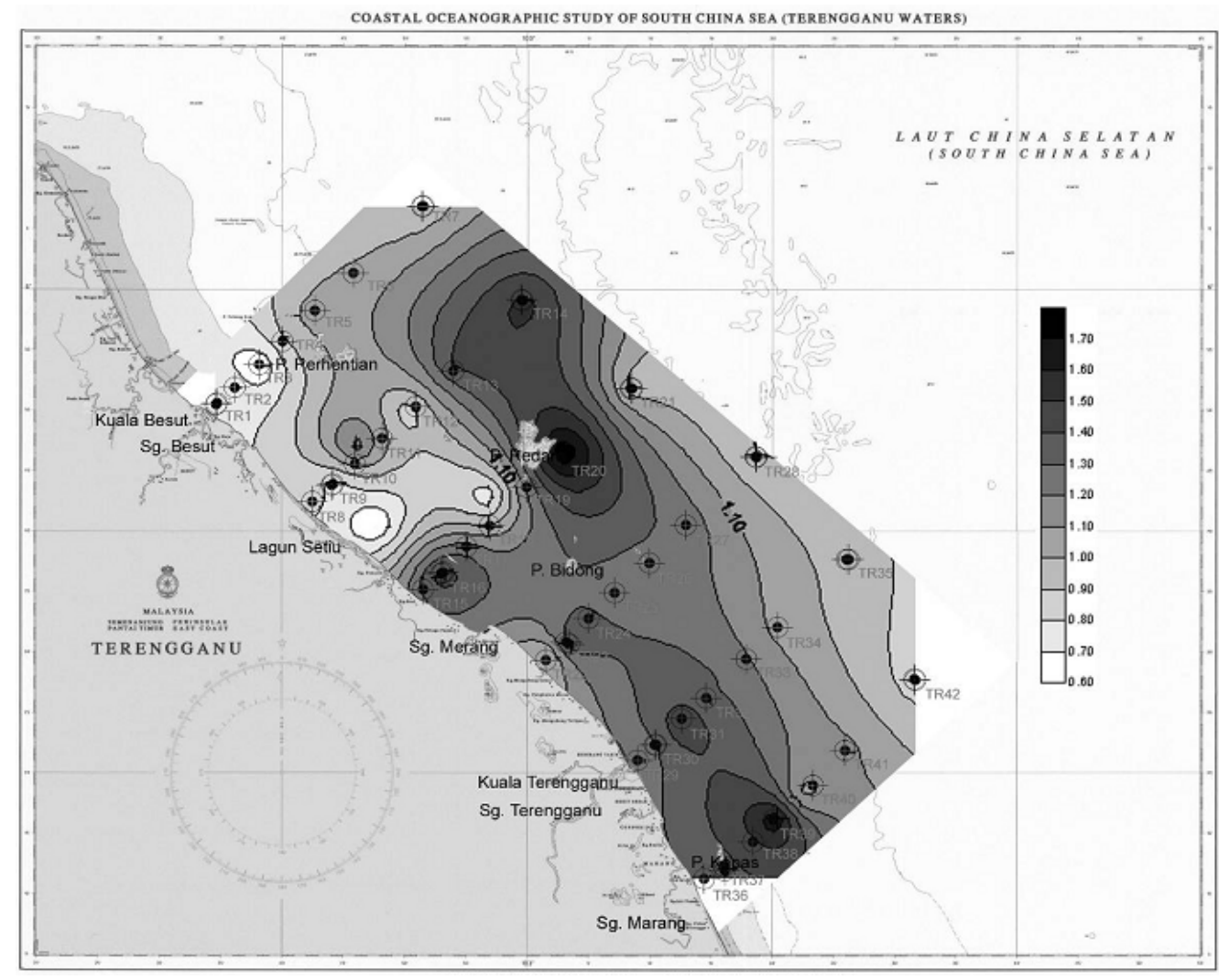

Fig. 2a: The distribution of organic carbon in Terengganu coastal water during the pre monsoon season 


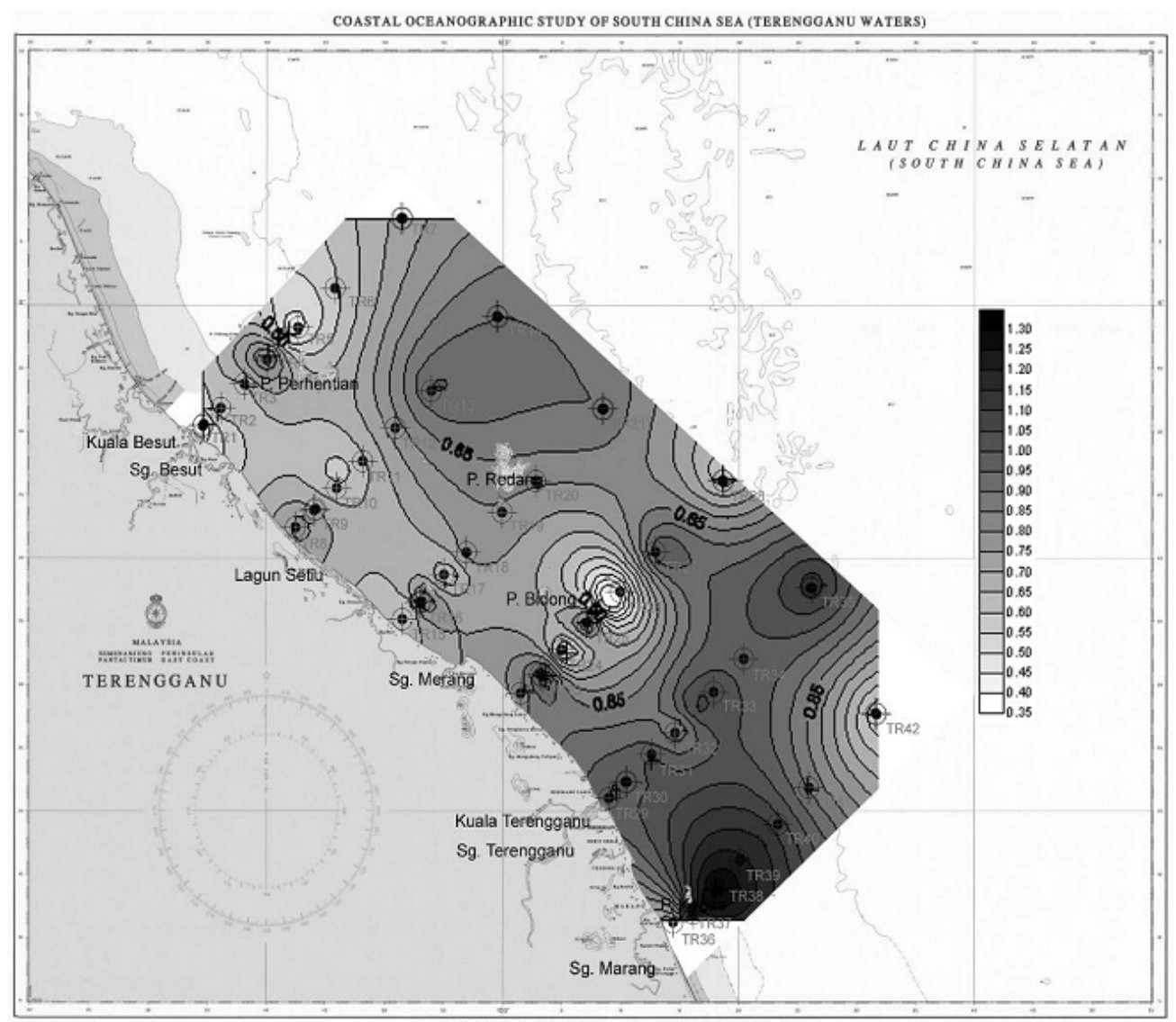

Fig. 2b: The distribution of organic carbon in Terengganu coastal water during the post monsoon season

which are reported to contribute to organic carbon adjacent to the estuary and nearshore area ${ }^{[9]}$. This situation was obvious during the pre-monsoon season, where the highest concentration of organic carbon was observed surrounding the island which in between the Terengganu River and Merang River. However, after pre-monsoon season, organic carbon was entirely drifted away towards the open sea and apparently reduced the concentration of organic carbon in Terengganu water. Gao et al.$^{[6]}$ reported that the content of organic carbon varied from $0.2-0.3 \%$ in the SCS; this is comparable with to the variation of organic carbon in the Terengganu water between the pre-monsoon and post-monsoon season, which was about $0.3 \%$. Marchand et al. ${ }^{[10]}$ stated that the association of organic carbon in sediment is crucially dependent upon the grain size itself, whereby higher organic content will be represented in the finer particles and vice versa. Thus, low organic carbon concentration in the study area may be due to the sediment grain size which was dominated by moderately coarse sand.

The correlation between mean sediment size and organic carbon was positive for both during pre and post-monsoon, respectively. This indicates that organic carbon may indeed higher in the finer particles. Meanwhile, the post-monsoon season showed a slightly higher value of r-squared correlation sediment size and organic carbon concentration. This condition indicates that sediment mean size was relatively higher during the premonsoon season than in the post-monsoon season. Thus, it is shown that the seasonal change between south west and north east monsoon has influenced the sediment characteristics and the organic carbon concentration in Terengganu water. According to some researcher ${ }^{[11,12]}$, in river and mangrove region, about $10-20 \%$ of organic carbon was found bonded to the finer particle $(<4 \mu \mathrm{m})$. Therefore, the low organic carbon content in Terengganu water might be due to the sediment grain size, which was about $250 \mu \mathrm{m}$ on the average.

\section{CONCLUSION}

The concentration of organic carbon was particularly high in the coastal area of Terengganu and the area surrounding the Island. It is likely that 
the high concentration of organic carbon were due to the river outfall of organic matter from land run-off. Similarly, around the Island, organic carbon may be contributed from settlement around the island.

\section{ACKNOWLEDGEMENT}

This research was funded from the Malaysian Ministry of Science under the Intensified Research for Priority Areas (IRPA). The authors wish to express their gratitude to the lab assistant of the Oceanography laboratory teams for their invaluable assistance and hospitality throughout the sampling period.

\section{REFERENCES}

1. Hung, J.J., S.M. Wang and Y.L. Chen, 2007. Biogeochemical controls on distributions and fluxes of dissolved and particulate organic carbon in the Northern South China Sea. DeepSea Res. Part II, 54: 1486-1503. DOI: $10.1016 /$ j.dsr2.2007.05.006.

2. Cha, H.J., M.S. Choi, C.B. Lee and D.H. Shin, 2007. Geochemistry of surface sediments in the Southwestern East/Japan Sea. J. Asian Earth Sci., 29: 685-697.

DOI: 10.1016/j.jseaes.2006.04.009.

3. Tesi, T., S. Miserocchi, M.A. Goňi, L. Langone, A. Bolfrin and M. Turchetto, 2007. Organic matter origin and distribution in suspended particulate materials and surficial sediments from the Western Adriatic Sea (Italy). Estuarine Coastal Shelf Sci., 73: 431-446. DOI: 10.1016/j.ecss.2007.02.008.

4. Burns, K.A., G. Brunskill, D. Brinkman and I. Zagorskis, 2008. Organic carbon and nutrient fluxes to the coastal zone from the sepik river outflow. Continental Shelf Res., 28: 283-301. DOI: 10.1016/j.csr.2007.08.004.

5. Goni, M.A., M.J. Teixeira and D.W. Perkey, 2003. Sources and distribution of organic matter in a river-dominated estuary (Winyah Bay, SC, USA). Estuarine Coastal Shelf Sci., 57: 1023-1048. DOI: $10.1016 / \mathrm{S} 0272-$ 7714(03)00008-8.
6. Gao, X.L., S.Y. Chen, X.L. Xie, A.M. Long and F.J. Ma, 2007. Non-aromatic hydrocarbons in surface sediments near the pearl river estuary in the South China Sea. Environ. Pollut., 148: 40-47. DOI: 10.1016/j.envpol.2006.11.001.

7. Hung, C.C., G.C. Gong, H.Y. Chen, H.L. Hsieh, P.T. Santschi, T.L. Wade and J.L. Sericano, 2007. Relationships between pesticides and organic carbon fractions in sediments of the Danshui River estuary and adjacent coastal areas of Taiwan. Environ. Pollut., 148: 546-554. DOI: 10.1016/j.envpol.2006.11.036.

8. Warnken, K.W., P.H. Santschi, K.A. Roberts and G.A. Gill, 2008. The cycling and oxidation pathways of organic carbon in a shallow estuary along the texas gulf coast. Estuarine Coastal Shelf Sci., 76: 69-84.

DOI: 10.1016/j.ecss.2007.06.010.

9. Tesi, T., S. Miserocchi, M.A. Goňi and L. Langone, 2007. Source, transport and fate of terrestrial organic carbon on the Western Mediterranean Sea, Gulf of Lions, France. Mar. Chem., 105: 101-117. DOI: 10.1016/j.marchem.2007.01.005.

10. Marchand, C., E. Lallier-Vergès, J.R. Disnar and D. Kéravis, 2008. Organic carbon sources and transformations in mangrove sediments: A rockeval pyrolysis approach. Organ. Geochem., 39: $408-421$.

DOI: 10.1016/j.orggeochem.2008.01.018.

11. Coppola, L., O. Gustafsson, P. andersson, T.I. Eglinton, M. Uchida and A.F. Dickens, 2007. The importance of ultrafine particles as a control on the distribution of organic carbon in Washington Margin and Cascadia Basin sediments. Chem. Geol., 243: 142-156. DOI: 10.1016/j.chemgeo.2007.05.020.

12. Soto-Jimenez, M., F. Paez-Osuna and A.C. Ruiz-Fernandez, 2003. Geochemical evidences of the anthropogenic alteration of trace metal composition of the sediments of Chiricahueto marsh (SE Gulf of California). Environ. Pollut., 125: 423-432. DOI: 10.1016/S0269-7491(03)00083-6. 